\title{
Nucleolar organiser regions in small cell carcinoma of the bronchus
}

\author{
J CROCKER, J AYRES, J MCGOVERN
}

From the Departments of Histopathology and Respiratory Medicine, East Birmingham Hospital, Birmingham $\overrightarrow{\times}$

ABSTRACT An argyrophil technique for the demonstration of nucleolar organiser regions has been applied to routinely processed paraffin sections of 15 specimens of small cell carcinoma and 15 biop\$건 specimens infiltrated by lymphocytes. To avoid tautological problems, the nature of the specimess was confirmed by means of immunohistochemical staining for neurone specific enolase and leucocyle common antigen. The specimens of small cell carcinoma were readily differentiated from those containing lymphocytes by the argyrophil method, the range of mean number of nucleolar organiser regions per nucleus being $4 \cdot 2-7 \cdot 3$ for small cell carcinoma cells and $0 \cdot 9-1 \cdot 7$ for lymphocytes. Th 15 method separates malignant epithelial cells from benign lymphocytic cells and has potential in both clinical and research investigation of respiratory tumours.

\section{Introduction}

In 1972 specific areas on certain chromosomes were identified as the sites of ribosomal DNA (rDNA). ${ }^{1}$ Such areas, or rRNA genes, are called nucleolar organiser regions.' These regions have a distinct nucleoprotein structure, which has been used in their identification by means of an argyrophil staining method (AgNOR) when applied to metaphase chromosome spreads. ${ }^{2}$ The nucleolar organiser regions are acted on by RNA polymerase I to produce rRNA precursors for ribosomes and hence are believed to reflect nuclear activity. ${ }^{3}$ Cytogeneticists have used AgNOR staining to analyse genetic trisomies, particularly Down's syndrome. ${ }^{4}$

In paraffin sections of malignant prostatic tissue nucleolar organiser regions occurred in greater numbers than in prostatic tissue showing benign hyperplasia. ${ }^{3}$ The use of the AgNOR technique in the assessment of grades of malignancy in paraffin sections of tumours was recently described for lymphomas $^{5}$ and melanotic skin lesions. ${ }^{6}$ In lymphomas there was a significant difference in the numbers of AgNORs in the nuclei between low grade lymphomas (1-1.5/nucleus) and high grade lymphomas (4.4-6.8/nucleus). Thus the AgNOR method,

Address for reprint requests: Dr J Crocker, Department of Histopathology, East Birmingham Hospital, Birmingham B9 5ST.

Accepted 26 June 1987 which is rapid and simple to apply, offers a ne method for the assessment of malignancy.

Small cell carcinoma of the bronchus may be a difficult diagnostic problem histologically, especia $\overrightarrow{0} y$ in the small samples obtained at bronchoscopy, ${ }^{7}$ both in differentiating it from other tumour types and differentiating malignant cells from lymphocytes. have therefore studied small cell carcinoma and brof chial inflammatory tissue to determine whether $\mathrm{Ag}$ NOR numbers help to distinguish between these two cell types.

\section{Methods}

Fifteen cases of small cell (oat cell) carcinoma we studied, 10 samples taken at fibreoptic bronchoscopy and five samples of excised tumour. Fifteen samples $8 \mathrm{f}$ bronchial tissue obtained at fibreoptic bronchosco containing a lymphocytic infiltrate were also studies. The specimens were taken from inflamed areas bronchoscopy, performed to rule out a diagnosis ef bronchial carcinoma. None of these latter patients hæ्षd carcinoma. Tissue was fixed in $10 \%$ formol saline and processed to paraffin wax. Sections were cut at $3 \mu$ thickness and submitted for AgNOR staining. ${ }^{5}$ क brief, sections were dewaxed and taken to watef. Deionised distilled water was used as a wash a medium. The reaction mixture was made up by dissolving gelatin in $1 \%$ aqueous formic acid to makge 


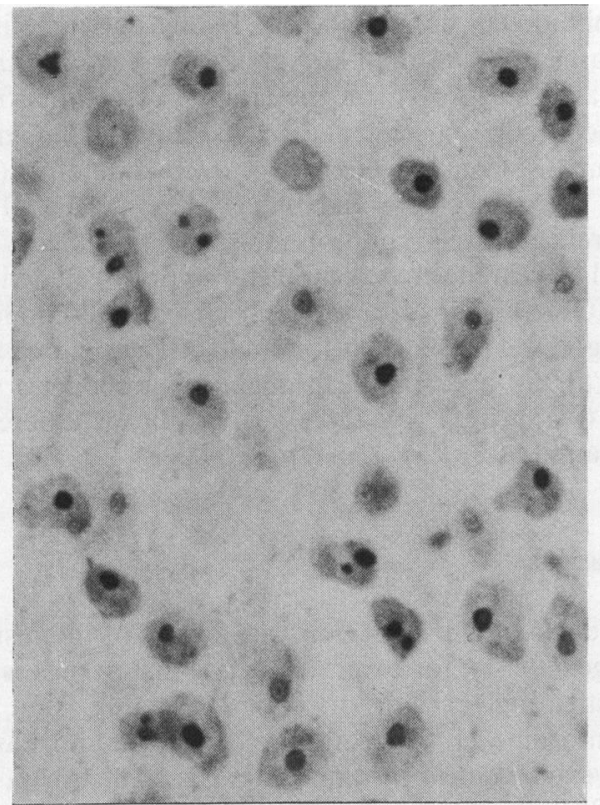

(a)

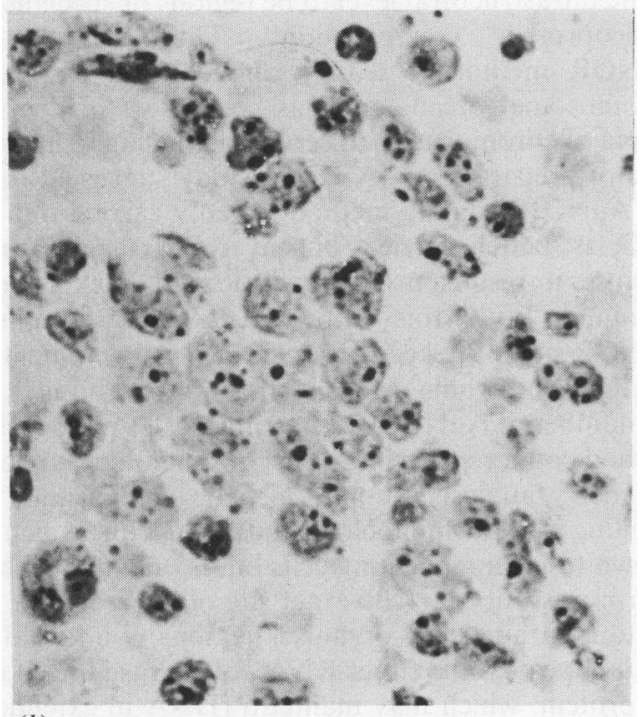

(b)

a $2 \%$ solution. This was mixed with $50 \%$ aqueous silver nitrate solution in a proportion of $1: 2$. Sections were incubated at room temperature in this mixture for 30 minutes, washed, taken to xylene, and mounted in synthetic medium. The number of stained nucleolar organiser regions (AgNORs) in 100 cells of each defined type were counted in all specimens with a standard graticule (to prevent recounting). Careful focusing allowed ready enumeration of each dot of AgNOR staining product. The counts were performed

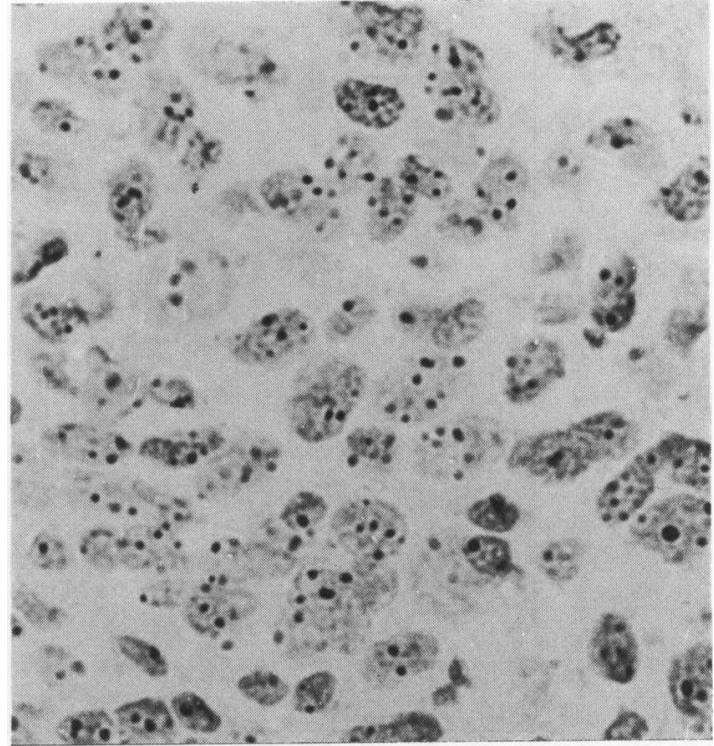

(c)

Fig 1 (a) Bronchial lymphocytic inflammatory infiltrate in a bronchial biopsy specimen showing one nucleolar organiser region, stained by an argyrophil technique, per nucleus. (b) Multiple stained nucleolar organiser regions in each nucleus in an excised specimen of small cell carcinoma. (c) Multiple stained nucleolar organiser regions in each nucleus in a biopsy specimen containing small cell carcinoma.

blind before immunohistochemical staining. The mean number of AgNORs per nucleus was calculated. Sections were also stained by means of indirect immunohistochemical (peroxidase label) techniques for leucocyte common antigen ${ }^{89}$ and neurone specific enolase. $^{10}$

\section{Results}

Staining for neurone specific enolase was positive and 


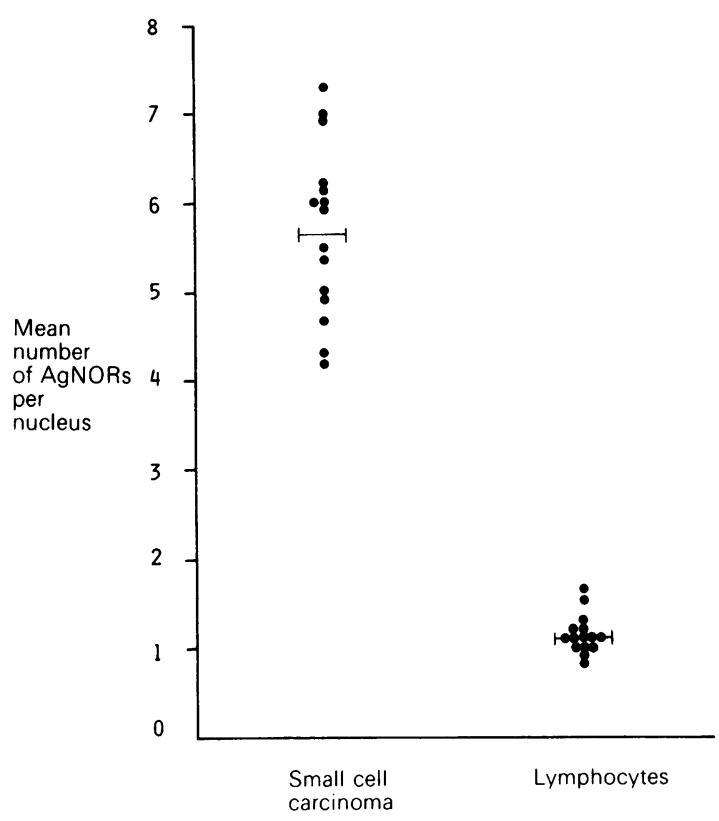

Fig 2 Mean number of nucleolar organiser regions stained by the argyrophil technique (AgNORs) per nucleus in 15 small cell carcinomas and 15 specimens of bronchus with a lymphocytic inflammatory infiltrate. The bars indicate the mean values for the group.

for leucocyte common antigen negative in all of the tumours taken to be small cell carcinomas and in none of the presumed inflammatory tissue, while the presumed lymphocytic infiltrates were reactive with the antibody to leucocyte common antigen but not with the antibody to neurone specific enolase. The

Mean numbers of nucleolar organiser regions stained in each specimen examined

\begin{tabular}{lll}
\hline & Lymphocytes & $\begin{array}{l}\text { Small cell } \\
\text { carcinoma cells }\end{array}$ \\
\hline & 0.9 & 6.2 \\
& 1.3 & 4.9 \\
& 1.1 & $7 \cdot 3$ \\
& 1.7 & 7.0 \\
& 1.1 & $4 \cdot 3$ \\
& 1.0 & $4 \cdot 2$ \\
& 1.0 & 5.5 \\
& 1.2 & 6.0 \\
& 0.9 & 6.9 \\
& 1.1 & 6.0 \\
Mean & 1.2 & 5.4 \\
SD & 1.1 & $4 \cdot 7$ \\
SEM & 1.6 & 5.0 \\
& 1.0 & 5.9 \\
\hline
\end{tabular}

lymphoid cells contained usually one but sometimes two areas of black dot like AgNOR product (fig 1a). It? was as easy to perform the counts in sections from $\frac{\bar{\omega}}{\overline{6}}$ bronchoscopy specimens as in sections from gross $\widetilde{\widetilde{\Phi}}$ specimens. Counts were performed by one of us (JC) with a $5-10 \%$ reproducibility (that is, a $5-10 \%$ (s) difference between counts on the same specimen). The $\vec{\circ}$ small cell carcinomas contained multiple well definedAgNOR dots (figs $1 b$ and $1 c$ ). The mean (SD) number of AgNORs per nucleus for small cell carcinoma was $5.70(0.96)$, and for the bronchial lymphocytes was: $1 \cdot 16(0.23)$ (fig 2 and table)-a significant differenceñ (unpaired $t$ test: $t=17 \cdot 83, \mathrm{p}<0.0001$ ).

\section{Discussion}

Nucleolar organiser regions have been of interest to cytogeneticists for over a decade as a means of investigating certain trisomies, notably that of 3

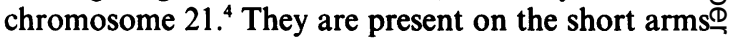
of five acrocentric chromosomes (Nos 13, 14, 15, 21 $\overrightarrow{x 0}$ and 22), where they appear as achromatic zones, seen at the ultrastructural level to be regions of specialised nucleoprotein configuration.' The argyrophiliog AgNOR method is readily applied to metaphases chromosome spreads and has been used to identify atypia of chromosomes in certain malignancies in this type of preparation. ${ }^{35} \mathrm{~A}$ recent study suggested that the AgNOR staining method, usually carried out atō $60^{\circ} \mathrm{C}$, is better carried out at room temperature because it results in a diminution in background staining. ${ }^{3}$ With this improved technique, manyAgNOR sites have been observed in certain malignant cell lines and whole cell centrifuge preparations. ${ }^{35}$ If the number of AgNORs represents a cell's ploidy, the method could replace or at least be an adjunct to flow 3 cytometry analysis. It may also be comparable to labelling with the monoclonal antibody $\mathrm{Ki67}$, which is known to label replicating cells but is only applicable to frozen sections. ${ }^{11}$ The exact site of argyrophilia in relation to nucleolar organiser regions is uncertain $\frac{D}{0}$ but it appears to be either RNA polymerase I itself or $\mathrm{C}_{23}$ protein, which may maintain rDNA in extended form. ${ }^{12}$

After greater numbers of AgNORs had been found in paraffin sections of a few prostatic carcinomas than in hyperplastic prostate and intervening lymphocytes the AgNOR stain has subsequently been applied to paraffin sections of human non-Hodgkin's lym phoma. ${ }^{5}$ Low grade malignancy non-Hodgkin's lym:phoma possessed about as many nucleolar organise 5 regions per nucleus as normal lymphocytes, whiled highly mitotic cells such as normal centroblasts an क्षि high grade non-Hodgkin's lymphoma possessed many more. The method has recently been applied to 
melanotic dermal lesions and differentiated between melanocarcinomas and naevocellular naevi. ${ }^{6}$

The AgNOR method is simple, reproducible, and rapid, requiring no repeated antibody incubations as in immunohistochemical reactions (for example, for neurone specific enolase and leucocyte common antigen). The reported numbers of AgNORs per nucleus are not absolute, being counts performed on 3 $\mu \mathrm{m}$ slices of tissue, and it should be stressed that, in the routine context, laborious AgNOR counts would be unnecessary, since lymphocytes possess "one" dot and small cell carcinoma cells have "many." There is one caveat-namely, that low grade non-Hodgkin's lymphoma cells contain about the same number of AgNORs as normal lymphocytes. Consequently, when small cell carcinoma has been excluded by this technique, other methods would have to be applied to determine whether a small lymphocytic infiltrate is benign or malignant.

This study has shown that the AgNOR staining method can readily distinguish between small cell carcinoma and lymphocytic infiltrates. In view of the similar appearance and size of the two cell types and the recognised frequent difficulty in distinguishing them histologically, ${ }^{7}$ this method has potential clinicopathological value, especially with bronchoscopic biopsy material, where the small size of the biopsy specimen and crush artefact cause problems in interpretation.

\section{References}

1 Henderson AS, Warburton D, Atwood KC. Location of ribosomal DNA in the human chromosomal com- plement. Proc Natl Acad Sci 1972;69:3394-8.

2 Howell WM, Black DA. Controlled silver staining of nucleolus organizer regions with a protective colloidal developer: a one-step method. Experientia 1980;36: 1014.

3 Ploton D, Menager M, Jeannesson P, Himber G, Pigeon $\mathrm{F}$, Adnet $\mathrm{JJ}$. Improvement in the staining and in the visualisation of the argyrophilic proteins of the nucleolar organiser region at the optical level. Histochem J 1986;18:5-14.

4 Markovic VD, Worton RG, Berg JM. Evidence for the inheritance of silver-stained nucleolus organizer regions. Hum Genet 1978;41:181-7.

5 Crocker J, Nar P. Nucleolar organizer regions in lymphomas. J Pathol 1987;151:111-8.

6 Crocker J, Skilbeck N. Nucleolar organiser region associated proteins in cutaneous melanotic lesions: a quantitative study. J Clin Pathol 1987;40:885-9.

7 Spencer H. Pathology of the lung. Vol 2. 4th ed. Oxford: Pergamon Press, 1985:877-84.

8 Crocker J, Jenkins R. An immunohistochemical study of branchial cysts. J Clin Pathol 1985;38:784-90.

9 Muller S, Sangster G, Crocker J, et al. An immunohistochemical and clinicopathological study of granulocytic sarcoma ("chloroma"). Hematol Oncol 1986;4:101-12.

10 Sloane JP, Ormerod MG. Immunohistological diagnosis of tumours In: Tumour markers in clinical practice. In: Daar AS, ed. Oxford: Blackwell Scientific Publications, 1987:242-310.

11 Gerdes J, Dallenbach F, Lennert K, Lemke H, Stein H. Growth fractions in malignant non-Hodgkin's lymphomas (NHL) as determined in situ with the monoclonal antibody Ki67. Hematol Oncol 1984;2: 365-71.

12 Olson MOJ, Thompson BA. Distribution of proteins among chromatin components of nucleoli. Biochemistry 1983;22:3187-93. 